\title{
Total anomalous pulmonary venous connection Repair using deep hypothermia and circulatory arrest in 44 consecutive infants
}

\author{
D F DICKINSON, K M PARIMELAZHAGAN, M C K TWEEDIE, C R WEST, G P PICCOLI, * \\ F MUSUMECI, ^ D I HAMILTON
}

From the Regional Paediatric Cardiothoracic Unit, Royal Liverpool Children's Hospital, Myrtle Street, Liverpool

SUMMARY Forty four consecutive infants aged from 3 days to 10 months underwent repair of total anomalous pulmonary venous connection using deep hypothermia with circulatory arrest. There were eight $(18 \%)$ early hospital deaths. Using multivariate analysis no significant association could be shown between early mortality and age or weight at operation, preoperative pulmonary or systemic pressure, and preoperative condition for patients undergoing operation during the most recent five year period. Late pulmonary venous obstruction developed in four (11\%) of the survivors and all of these patients died.

Total anomalous pulmonary venous connection is a relatively uncommon cardiac malformation representing less than $1 \%$ of all congenital cardiac anomalies. ${ }^{12}$ Without surgical treatment, the mortality within the first year of life is high, ${ }^{3}$ and those who survive may develop progressive pulmonary vascular disease. ${ }^{45}$ Early surgical intervention is therefore indicated in the majority of patients. Successful surgical correction was first reported by Muller in $1951^{6}$ and subsequently others described their experience in the surgical management of this lesion, using either hypothermia with inflow occlusion, ${ }^{7}$ or standard cardiopulmonary bypass. ${ }^{89}$ It is only with the adoption of deep hypothermia and circulatory arrest, however, that satisfactory results have been achieved in infancy. ${ }^{10^{-1}}$

In this paper, we review our experience during the last 12 years of single stage correction of total anomalous pulmonary venous connection in infancy using this latter technique.

\section{Patients and methods}

During the period January 1970 to December 1981, 44 consecutive infants under one year of age with total anomalous pulmonary venous connection underwent

${ }^{\star}$ G P Piccoli and F Musumeci were supported by a grant from the National Heart Research Fund.

Accepted for publication 13 April 1982 single stage surgical correction at the Royal Liverpool Children's Hospital, using deep hypothermia and circulatory arrest. Four infants who were operated on in 1970 and 1971 using standard cardiopulmonary bypass and previously reported ${ }^{13}$ are not included in this report. One further case also included in the previous report, ${ }^{13}$ with infracardiac total anomalous pulmonary venous connection occurring as part of a complex malformation associated with the asplenia syndrome is excluded since the operation was an attempt at palliation rather than correction.

The patients are grouped according to the site of pulmonary venous connection (Fig. 1). Twenty-two patients had supracardiac total anomalous pulmonary venous connection and nine had infracardiac total anomalous pulmonary venous connection. The group of eight patients with intracardiac total anomalous pulmonary venous connection includes six with drainage entirely to the coronary sinus and two with drainage direct to the right atrium. Five patients had a mixed type of total anomalous pulmonary venous connection. In four, part of the left upper lobe drained into the innominate vein, while the remaining veins entered the coronary sinus. The fifth patient had both upper lobe veins entering the superior vena cava while the lower lobe veins entered the right atrium via a common venous channel.

There were 22 male and 22 female patients ranging in age from 3 to 312 days (mean 77 days) at the time of operation. The weight at operation varied from $2.3 \mathrm{~kg}$ 


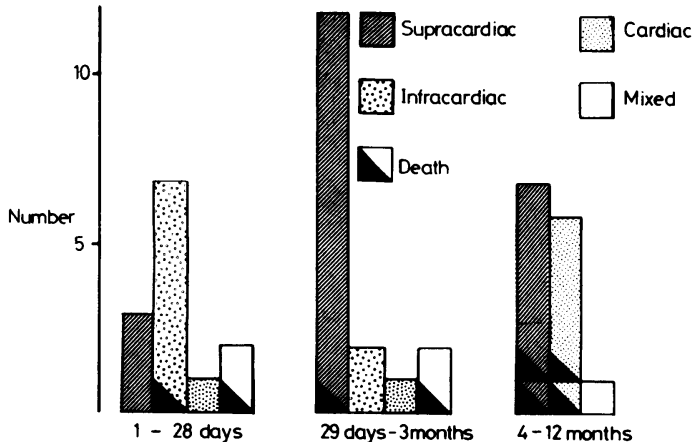

Fig. 1 Age at operation and anatomical type in 44 infants with total anomalous pulmonary venous connection.

to $8.7 \mathrm{~kg}$ (mean $3.9 \mathrm{~kg}$ ). One patient was known to have a ventricular septal defect and the ductus arteriosus was patent in a further 14 patients. Balloon septostomy was performed at the time of diagnostic catheterisation in nine patients: four with a supracardiac connection, three with drainage to the coronary sinus, and two with mixed total anomalous pulmonary venous connection.

\section{PREOPERATIVE CONDITION}

Each patient was assigned retrospectively to one of three groups according to the clinical condition at the time of diagnosis. Group 1 consisted of four infants whose symptoms were well controlled on medical treatment and who underwent operation electively at a mean interval of 122 days (range 95 to 155 days) from the time of presentation. In group 2 there were 27 infants with severe symptoms but no acute deterioration in whom operation seemed advisable without undue delay. These infants underwent surgery two to 54 days (mean 13 days) from the time of diagnosis. Group 3 consisted of 13 critically ill infants who underwent emergency operation at a mean interval of 2.8 days from the time of diagnosis (range less than one to eight days). Five patients in this group had supracardiac and eight had infracardiac total anomalous pulmonary venous connection. Eight of these patients were ventilated electively before operation because of respiratory failure. Critical preoperative status was correlated significantly with young age and with raised pulmonary and lowered systemic pressures at the time of cardiac catheterisation ( $p=0.05$ to 0.01 in each case; t tests, confirmed by MannWhitney tests).

All cases were operated on using deep hypothermia induced with core cooling, and total circulatory arrest using techniques described previously. ${ }^{13} 14$ For patients with supra- and infracardiac total anomalous pulmonary venous connection. a left anterolateral thoracotomy with transternal extension was used. ${ }^{15}$

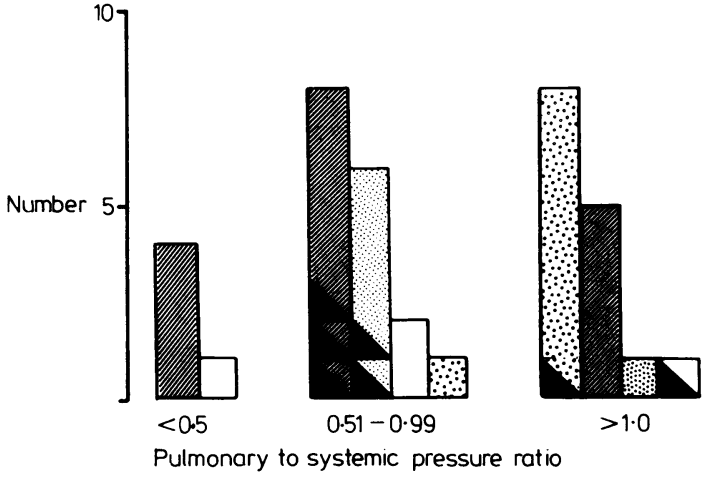

Fig. 2 Preoperative pulmonary to systemic pressure ratio and anatomical type in 37 infants with total anomalous pulmonary venous connection. Key as for Fig. 1.

Patients with cardiac or mixed types of total anomalous pulmonary venous connection were repaired through a median sternotomy. In three most recent patients with mixed total anomalous pulmonary venous connection predominantly to the coronary sinus the operation suggested by Van Praagh et al. ${ }^{16}$ for total anomalous pulmonary venous connection to the coronary sinus was used.

Preoperative measurements of pulmonary and systemic pressure were made in 37 patients and the pulmonary to systemic pressure ratios for each anatomical group are shown in Fig. 2.

\section{STATISTICAL ANALYSIS}

Seven factors were selected as having a possible influence on early mortality: anatomical type, age and weight at operation, preoperative condition, preoperative $\mathrm{PCO}_{2}$ (without assisted ventilation), preoperative pulmonary and systemic pressures, and the duration of circulatory arrest. Complete data were available for 29 consecutive patients operated on during the most recent five year period. These data were tabulated and the Statistical package for the social sciences ${ }^{17}$ was used for cross-tabulation, unpaired Student's $t$ test and discriminant analysis predicting early death or survival. Where necessary, transformation to $\frac{D}{O}$ a logarithmic scale was performed to normalise data before using Student's $t$ test.

\section{Results}

\section{EARLY MORTALITY}

Eight infants (18\%) died within 30 days of the operation. During the most recent five year period, 29 con- $\mathbb{D}$ secutive infants (11 supracardiac, eight infracardiac, seven cardiac, and three mixed) have undergone oper- 0 ation, with four early deaths (14\%), compared with $\stackrel{\vec{D}}{\vec{D}}$ four early deaths among 15 infants $(27 \%)$ during the 
preceding seven years. This difference is not statistically significant. Two of the deaths in the earlier period were the result of avoidable technical errors at the time of operation.

For the 29 patients undergoing operation during the most recent five year period, no significant association could be established between early death and anatomical type, age or weight at operation, preoperative condition, pulmonary or systemic pressures, $\mathrm{PCO}_{2}$, or duration of circulatory arrest. None of these variables was significantly different for early deaths as compared with other cases (unpaired Student's t test confirmed by Mann-Whitney rank sum test). Nor was any pattern discernible among the four early death cases on any two dimensional plot of any pair of continuous variables except in the case of the age/weight plot where they lay very closely on a straight line. The probability of early death, computed from a linear function on the logit scale by using the generalised linear interactive modelling package, ${ }^{18}$ did not depend significantly on any of the above mentioned variables. Linear discriminant analysis between the early deaths and the remaining patients using logarithmic transformations of age, weight, pulmonary and systemic pressure, and duration of circulatory arrest was also ineffective in predicting early death. During this period early death appeared to be a random event not clearly connected with any of the variables studied, either individually or in combination.

LATE RESULTS

Four patients developed pulmonary venous obstruc- tion, all within three months of the initial operation and all subsequently died. Postoperative cardiac catheterisation data on these patients are summarised in the Table. Case 1 underwent a second operation three months after the initial procedure. The orifices of three of the four pulmonary veins were found to be partly obstructed by intimal proliferation. An angioplastic procedure was performed to enlarge the pulmonary veins but the infant died four months later, with clinical evidence of reobstruction of the pulmonary veins. Case 2 was readmitted one month after the first operation. He deteriorated rapidly after investigation and died before a second operation could be performed. Consent for a necropsy was refused. Case 3 had total anomalous pulmonary venous connection to the coronary sinus. At the second operation the opening between the coronary sinus and the left atrium was severely stenotic with thickening of the tissue surrounding this ostium and shrinkage of the Dacron patch placed at the mouth of the coronary sinus. The original operation was revised but the patient died suddenly two months later. At necropsy the inlet of the coronary sinus to the left atrium was widely patent, but the four pulmonary veins entered the apex of the coronary sinus via a single stenotic orifice of less than $4 \mathrm{~mm}$ diameter. Case 4 had drainage of the pulmonary veins direct to the right atrium. He died before a second operation could be performed and at necropsy it was found that the right pulmonary veins were totally occluded by shrinkage and thickening of the original Dacron baffle used to redirect pulmonary venous blood into the left atrium.

The 32 longer term survivors have been reviewed

Table Postoperative cardiac catheterisation data in 11 patients

\begin{tabular}{|c|c|c|c|c|c|c|}
\hline \multirow[t]{2}{*}{ Case No. } & \multirow{2}{*}{$\begin{array}{l}\text { Anatomical } \\
\text { type }\end{array}$} & \multirow{2}{*}{$\begin{array}{l}\text { Interval after } \\
\text { operation } \\
\text { (mth) }\end{array}$} & \multicolumn{2}{|c|}{ Pressures $(\mathrm{mmHg})$} & \multirow{2}{*}{$\begin{array}{l}\text { Pulmonary to } \\
\text { systemic flow ratio }\end{array}$} & \multirow[t]{2}{*}{ Comment } \\
\hline & & & Pulmonary & Systemic & & \\
\hline 1 & Supracardiac & 3 & 100 & 65 & 1 & $\begin{array}{l}\text { Pulmonary venous obstruction; } \\
\text { reoperation; died }\end{array}$ \\
\hline 2 & Infracardiac & 1 & 65 & 120 & 1 & $\begin{array}{l}\text { Pulmonary venous obstruction; } \\
\text { died }\end{array}$ \\
\hline 3 & Cardiac & 3 & 80 & 75 & 1 & $\begin{array}{l}\text { Pulmonary venous obstruction; } \\
\text { reoperation; died }\end{array}$ \\
\hline 4 & Cardiac & 2 & 90 & 75 & 1 & $\begin{array}{l}\text { Pulmonary venous obstruction; } \\
\text { died }\end{array}$ \\
\hline 5 & Supracardiac & 59 & 21 & 100 & 2 & $\begin{array}{l}\text { Residual ASD; } \\
\text { successful operation }\end{array}$ \\
\hline 6 & Supracardiac & 16 & 78 & 84 & $1 \cdot 8$ & $\begin{array}{l}\text { Residual VSD; } \\
\text { successful operation }\end{array}$ \\
\hline 7 & Infracardiac & 1 & 35 & 80 & 1 & $\begin{array}{l}\text { Transient pericardial } \\
\text { effusion; good result }\end{array}$ \\
\hline 8 & Cardiac & 13 & 36 & 80 & 1 & $\begin{array}{l}\text { Good haemodynamic result; } \\
\text { atrioventricular block }\end{array}$ \\
\hline $\begin{array}{r}9 \\
10 \\
11\end{array}$ & $\begin{array}{l}\text { Cardiac } \\
\text { Cardiac } \\
\text { Mixed }\end{array}$ & $\begin{array}{r}12 \\
26 \\
3\end{array}$ & $\begin{array}{l}28 \\
23 \\
28\end{array}$ & $\begin{array}{r}100 \\
110 \\
95\end{array}$ & $\begin{array}{l}1 \\
1 \\
2 \cdot 2\end{array}$ & $\begin{array}{l}\text { Good result } \\
\text { Good result } \\
\text { Residual ASD; } \\
\text { awaiting reoperation }\end{array}$ \\
\hline
\end{tabular}

ASD, atrial septal defect; VSD, ventricular septal defect. 
regularly with a follow up ranging from three months to 10 years (mean $5 \cdot 1$ years). One child (case 5 , Table) required a second operation to close a residual atrial septal defect and a second (case 6, Table) has had a second operation to close a ventricular septal defect. A further five patients have been investigated postoperatively (Table). Four have a good haemodynamic result but one has atrioventricular block and one had a transient pericardial effusion at the time of investigation. Two of these patients were investigated because of a slight suspicion on clinical grounds that pulmonary venous obstruction was developing but these suspicions were unfounded. Pulmonary venous obstruction has not been identified in any patient as a later postoperative complication. The last patient (case 11, Table) has a residual atrial shunt after repair of a mixed type of total anomalous pulmonary venous connection and will need a second operation in the future.

The remaining patients are clinically well with no abnormal signs in the cardiovascular system other than wide splitting of the second heart sound and mild cardiomegaly on chest $x$-ray.

\section{Discussion}

Before 1970, the surgical mortality for correction of total anomalous pulmonary venous connection in infancy was significantly higher than in older patients and some authors regarded young age as a major factor in determining early mortality. ${ }^{19}$ During the past decade, improved results have been achieved particu-

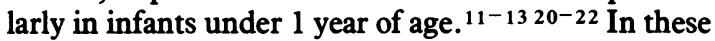
series, young age at operation has not been confirmed as a risk factor and our present results substantiate this view. During the 12 year period reviewed, there were no deaths among five patients operated on during the first week of life showing that even the youngest patients can be corrected successfully. Though we were unable to show a correlation between preoperative condition and early mortality this is only likely to be the case if the operation is performed with an appropriate degree of urgency. We agree with the view expressed by many authors 11122021 that any delay in the effective surgical treatment of symptomatic infants, particularly when pulmonary venous return is obstructed, may result in a higher operative mortality rate.

Surgical mortality in the patients reported by Clarke et al. ${ }^{12}$ and Turley et al. ${ }^{20}$ was most closely related to the anatomical type of total anomalous pulmonary venous connection present. During our most recent experience no such correlation was present with survival of all three patients with mixed total anomalous pulmonary venous connection. It should be noted, however, that these patients had a relatively $\stackrel{\vec{C}}{\mathrm{C}}$ simple type of mixed total anomalous pulmonary ven- $\overrightarrow{\vec{F}}$ ous connection predominantly to the coronary sinus. $\stackrel{\text { ? }}{-}$ In more complex types a higher mortality might be등 expected. ${ }^{21}$ It is interesting that the anatomical type $\frac{\bar{\sigma}}{\bar{N}}$ carrying the highest mortality in the series of Clarke $e t \overrightarrow{{ }_{0}}$ $a l .{ }^{12}$ Turley et al., ${ }^{20}$ and Hammon et al. ${ }^{22}$ (infracar- $\bigcirc$ diac) carried the lowest mortality among our patients. क Conversely, we have experienced a relatively high $\overrightarrow{0}$ early mortality among patients with the intracardiac type of the anomaly, a defect which in other $\vec{\omega}$ hands ${ }^{111220}$ carries a low mortality. The number of $\frac{\mathscr{T}}{\partial}$ deaths in each series, however, is small and many

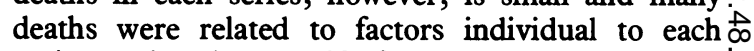
patient rather than specific for a particular anatomical $\omega$ type. For example, two deaths in the present series is and two deaths among the patients reported by Whight et al. ${ }^{11}$ were mainly the result of avoidable $\stackrel{5}{5}$ technical errors unrelated to the particular anatomical $\vec{D}$ type present. Reviewing the combined recent experi- $\frac{D}{0}$ ence of the groups in Auckland, Boston, and $\overrightarrow{\mathbb{D}}$ Birmingham, Katz et al. ${ }^{21}$ concluded that anatomical $\bar{\sigma}$ type was not a determinant of early mortality except $\stackrel{\Phi}{工}$ in the case of patients with the complicated mixed $\vec{\bullet}$ type of total anomalous pulmonary venous connection. Our results show that an early mortality of less than $15 \%$ should be expected in patients with the supra- and infracardiac types. Others ${ }^{11} 1220$ have shown that a similar or lower mortality can be achieved with total anomalous pulmonary venous $\frac{\partial}{\square}$ connection to the right atrium or coronary sinus.

Though late mortality after correction of total $\vec{O}$ anomalous pulmonary venous connection is low, ${ }^{23}$ in 3 many recently reported series there has been significant mortality and morbidity associated with? the development of pulmonary venous obstruction. 112024 Four (11\%) of the 36 hospital survivors in our series developed this complication, all within three months of the original operation. In one case, 3 the main reason for obstruction appeared to be related to shrinkage and thickening of a synthetic Dacron patch, but in two cases, one with supracardiac drain-o age and one with the coronary sinus type, obstruction developed at the orifices of the pulmonary veins at ao site remote from any suture line. The cause of obstruction in the fourth case was not determined. $/$ Though pulmonary venous obstruction has been N described in patients with total anomalous pulmonary స్ల venous connection before surgical treatment, ${ }^{3}$ there ${ }_{\sigma}$ was no evidence of this in any of our patients. Similar findings have been reported by other authors. Both Turley et al. ${ }^{20}$ and Fleming et al. ${ }^{24}$ reported cases of infradiaphragmatic total anomalous pulmonary venous connection developing pulmonary venous obs-ō truction at a site proximal to the original anastomosis. In the study of Whight et al. ${ }^{11}$ three patients with 
total anomalous pulmonary venous connection to the coronary sinus developed pulmonary venous obstruction, caused in one case by thickening of a pericardial patch and in two further cases by partial obliteration of the ostia of the pulmonary veins by fibrosis. Surgical treatment of pulmonary vein obstruction is difficult $^{1120}$ and the problem may recur even after apparently successful reoperation. ${ }^{20}$ Its occurrence is unpredictable and though it appears to be more common after repair of the infradiaphragmatic type, it is by no means confined to that group.

Several approaches have been used to gain optimal exposure of the anomalous venous channels in supraand infracardiac total anomalous pulmonary venous connection. Throughout the 12 year period, we have used the left anterolateral thoracotomy advocated by Roe. ${ }^{15}$ It has been suggested that aortic cannulation might prove to be difficult using this approach and that cannulation of the descending aorta might be necessary. ${ }^{15}$ With trans-sternal extension of the incision, however, we have not found this to be the case. In our experience, the left anterolateral thoracotomy gives excellent exposure of the left atrium and common pulmonary vein and facilitates the construction of the largest possible anastomosis in spite of the small size of the left atrium in this anomaly. ${ }^{25} 26$ If necessary, the incision can be extended onto the left atrial appendage which is usually of relatively normal size. ${ }^{26}$ We have not found it necessary during this 12 year period to enlarge the size of the atrial cavity in any patient either by using a patch or by moving the interatrial septum to the right. No problems with kinking of the anastomosis have been encountered and pulmonary venous obstruction at the suture line has not been recognised as a late complication in any patient with these anatomical types of total anomalous pulmonary venous connection.

Several authors ${ }^{112225}$ have published their findings at cardiac catheterisation carried out one to six years after operation for total anomalous pulmonary venous connection. Their findings show normal or near normal right and left ventricular and left atrial volumes, with normal right ventricular pressures in the majority of asymptomatic survivors. Unexpected major residual defects were not identified. In view of these encouraging reports, we have studied our postoperative patients only when specific clinical indications were present.

Conventional repair of total anomalous pulmonary venous connection to the coronary sinus involves incising the margin of the coronary sinus and carrying the incision back through the foramen ovale into the left atrium. A large patch is then used to roof over the combined orifice of the coronary sinus and fossa ovale. An alternative procedure was suggested by Van Praagh et al. ${ }^{16}$ in 1972 . Though the procedure was originally devised to avoid damage to internodal conduction pathways, its main advantage appears to be the avoidance of prosthetic material within the atrium of a small infant. In view of the problems encountered after patch shrinkage both in our patients and those reported by Whight et al., ${ }^{11}$ this advantage appears to be considerable. We have used this method in three recent cases with mixed type total anomalous pulmonary venous connection predominantly to the coronary sinus and intend to use it more extensively in the future.

The role of balloon atrial septostomy in the management of the infant with total anomalous pulmonary venous connection remains a subject for debate. Left heart filling in this condition is entirely dependent on a right to left atrial shunt, and the atrial septum may be a site of obstruction even in patients with no pressure gradients between left and right atrium. ${ }^{26} \mathrm{Bal}$ loon septostomy has therefore been recommended for all infants with total anomalous pulmonary venous connection as a means of palliating the symptomatic infant. ${ }^{27} 28$ Patients with pulmonary venous obstruction are unlikely to be benefited. The procedure, however, may be helpful in infants in whom the pulmonary venous return is unobstructed, pulmonary artery pressure is less than half systemic, and postponement of operation for a short period is desired. Whight et al. ${ }^{11}$ have drawn attention to a possible disadvantage of balloon septostomy in patients with total anomalous pulmonary venous connection to the coronary sinus in whom the Van Praagh technique ${ }^{16}$ is to be used for repair, in that closure of the atrial septum may be easier if the fossa ovale is intact. We have used balloon atrial septostomy in nine patients in an attempt to improve left heart filling preoperatively. Though it has been suggested that septostomy may be difficult in total anomalous pulmonary venous connection, ${ }^{27}$ using biplane screening facilities, the procedure has not been accompanied by any morbidity in our patients. We do not, however, regard this procedure as a substitute for urgent surgical treatment in the majority of patients.

Our experience with the management of infants with total anomalous pulmonary venous connection during the past 12 years suggests that the best results are obtained when referral to a specialised paediatric cardiac unit is made as soon as the diagnosis is suspected, preferably during the first weeks of life. Since surgical mortality is not correlated with young age, operation should be performed on an emergency or semi-emergency basis as the patient's condition demands. Unnecessary delay is likely to lead to acute deterioration particularly when pulmonary venous obstruction is present. The long term results and excellent health of the surviving children are just reward to the medical and surgical team who accept 
the considerable challenge which these seriously ill infants present on admission to hospital.

\section{References}

1 Hoffman JIE, Christianson R. Congenital heart disease in a cohort of 19,502 births with long-term follow up. Am f Cardiol 1978; 42: 641-7.

2 Dickinson DF, Arnold R, Wilkinson JL. Congenital heart disease among 160,480 liveborn children in Liverpool 1960 to 1969 . The implications for surgical treatment. Br Heart f 1981; 46: 55-62.

3 Gathman GE, Nadas AS. Total anomalous pulmonary venous connection. Clinical and physiologic observations of 75 pediatric patients. Circulation 1970; 42: 143-54.

4 Haworth SG, Reid L. Structural study of pulmonary circulation and of heart in total anomalous pulmonary venous return in early infancy. Br Heart $\mathcal{F}$ 1979; 39: 80-92.

5 Newfeld EA, Wilson A, Paul MH, Reisch JS. Pulmonary vascular disease in total anomalous pulmonary venous drainage. Circulation 1980; 61: 103-9.

6 Muller WH Jr. The surgical treatment of transposition of the pulmonary veins. Ann Surg 1951; 134: 683-93.

7 Lewis FJ, Varco RL, Taufic M, Niazi SA. Direct vision repair of triatrial heart and total anomalous pulmonary venous drainage. Surg Gymecol Obstet 1956; 102: 713-20.

8 Cooley DA, Ochsner A Jr. Correction of total anomalous pulmonary venous drainage. Surgery 1957; 42: 1014-21.

9 Cooley DA, Hallman GL, Leachman RD. Total anomalous pulmonary venous drainage: correction with the use of cardiopulmonary bypass in 62 cases. $f$ Thorac Cardiovasc Surg 1966; 51: 88-102.

10 Dillard DH, Mohri H, Hessel EA, et al. Correction of total anomalous pulmonary venous drainage in infancy utilizing deep hypothermia with total circulatory arrest. Circulation 1967; 35, suppl 1: 105-10.

11 Whight CM, Barratt-Boyes BG, Calder AL, Neutze JM, Brandt PWT. Total anomalous pulmonary venous connection. Long-term results following repair in infancy. $\mathcal{F}$ Thorac Cardiovasc Surg 1978; 75: 52-63.

12 Clarke DR, Stark J, De Leval M, Pincott JR, Taylor JFN. Total anomalous pulmonary venous drainage in infancy. Br Heart $\mathcal{F}$ 1977; 39: 436-44.

13 Di Eusanio G, Sandrasagra FA, Donnelly RJ, Hamilton DI. Total anomalous pulmonary venous connection (surgical technique, early and late results). Thorax 1978; 33: 275-82.

14 Hamilton DI, Shackleton J, Rees GJ, Abbott T. Experience with deep hypothermia in infancy using core cooling. In: Barratt-Boyes BG, Neutze JM, Harris EA, eds. Heart disease in infancy. Edinburgh and London: Churchill Livingstone, 1973: 52-74.

15 Roe BB. Posterior approach to correction of total anomalous pulmonary venous return. $\mathcal{f}$ Thorac Cardiovasc Surg 1970; 59: 748-53.

16 Van Praagh R, Harken AH, Delisle G, Ando M, Gross $\mathrm{RE}$. Total anomalous pulmonary venous drainage to the coronary sinus. F Thorac Cardiovasc Surg 1972; 64: 1325.

17 Nie NH, Hull CH, Jenkins JG, Steinbrenner K, Bent BH. Statistical package for the social sciences. 2nd ed. New York: McGraw-Hill, 1975.

18 Baker RJ, Nelder JA. The GLIM system. Release 3. Oxford: Numerical Algorithms Group, 1978.

19 Wukasch DC, Deutsch M, Reul GJ, Hallman GL, Cooley DA. Total anomalous pulmonary venous return: review of 125 patients treated surgically. Ann Thorac Surg 1975; 19: 622-33.

20 Turley K, Tucker -WY, Ullyot DJ, Ebert PA. Total anomalous pulmonary venous connection in infancy: influence of age and type of lesion. Am $\mathcal{F}$ Cardiol 1980; 45: 92-7.

21 Katz NM, Kirklin JW, Pacifico AD. Concepts and practices in surgery for total anomalous pulmonary connection. Ann Thorgc Surg 1978; 25: 479-87.

22 Hammon JW Jr, Bender HW Jr, Graham TP Jr, Boucek RJ Jr, Smith CW, Erath HG Jr. Total anomalous pulmonary venous connection in infancy. Ten years' experience including studies of postoperative ventricular function. I Thorac Cardiovasc Surg 1980; 80: 544-51.

23 Macartney FJ, Taylor JFN, Graham GR, De Leval M, Stark J. The fate of survivors of cardiac surgery in infancy. Circulation 1980; 62: 80-91.

24 Fleming WH, Clark EB, Dooley KJ, et al. Late complications following surgical repair of total anomalous pulmonary venous return below the diaphragm. Ann Thorac Surg 1979; 27: 435-9.

25 Graham TP Jr, Jarmakani JM, Canent RV Jr. Left heart volume characteristics with a right ventricular volume overload: total anomalous pulmonary venous connection and large atrial septal defect. Circulation 1972; 45: 38996.

26 Mathew R, Thilenius OG, Replogle RL, Arcilla RA. Cardiac function in total anomalous pulmonary venous return before and after surgery. Circulation 1977; 55: 361-70.

27 El-Said G, Mullins CE, McNamara DG. Management of total anomalous pulmonary venous return. Circulation 1971; 45: 1240-50.

28 Mullins CE, El-Said GM, Neches WH, et al. Ballon atrial septostomy for total anomalous pulmonary venous return. Br Heart $\mathcal{F}$ 1973; 35: 752-7.

Requests for reprints to $\mathrm{Mr}$ DI Hamilton, Royal Liverpool Children's Hospital, Myrtle Street, Liverpool L7 7DG. . 